\title{
Advanced therapies in pulmonary arterial hypertension and congenital heart disease in people with Down syndrome
}

\author{
Zoya Rashid ${ }^{1}$ and Robert Tulloh ${ }^{1,2^{*}}$
}

\begin{abstract}
Background: Management of patients with pulmonary arterial hypertension associated with congenital heart disease and trisomy 21 is complex due to uncertainty over the best first-line agent to use for treatment, and the outcome measures for assessing response to therapy. There are also ethical issues around therapeutic decisions which may require 'best interests' meetings of carers and health care professionals.

Case presentation: We present a case of a 35-year-old man with Down syndrome, with un-operated atrioventricular septal defect, right ventricular hypertrophy and moderate left atrioventricular valve regurgitation. In the clinic he was visibly cyanosed with peripheral oxygen saturations of $78 \%$ at rest. He had very limited walk distance and was in WHO class III.

Conclusions: We discuss the decisions made around the best therapy for his Eisenmenger syndrome taking into account patient and family views on therapy and considering the psychosocial burden of treatment.
\end{abstract}

Keywords: Pulmonary hypertension, Eisenmenger syndrome, Congenital heart disease, Down syndrome

\section{Background}

Pulmonary arterial hypertension (PAH) is the combination of a mean pulmonary arterial pressure greater than $25 \mathrm{mmHg}$, elevated pulmonary vascular resistance, a low left atrial pressure and absence of other causes of precapillary disease such a chronic thromboembolic pulmonary hypertension or lung disease [1]. Eisenmenger syndrome (ES) occurs when any untreated congenital heart disease causes reversal of systemic-to-pulmonary shunt secondary due to increased pulmonary vascular resistance [2]. Down syndrome (DS) patients with ES represent a unique subset of patients requiring a combined multidisciplinary approach to treatment due to the multifactorial nature of their pulmonary hypertension [3].

\footnotetext{
* Correspondence: Robert.Tulloh@bristol.ac.uk

'Bristol Congenital Heart Centre and Biomedical Research Centre, Bristol Heart Institute and Bristol Medical School, Bristol, UK

${ }^{2}$ Department of Congenital Heart Disease, Congenital Cardiology and

Pulmonary Hypertension, Upper Maudlin Street, BS2 8BJ Bristol, UK
}

Data from the German National Register for Congenital Heart Defects highlighted the detrimental impact of ES on survival of DS patients with post-tricuspid shunt lesions [4]. Stratification of DS patients by the presence of ES indicated that survival is more greatly influenced by the presence of ES than DS. However, earlier detection and repair of heart defects has led to the percentage of DS patients who develop ES falling to less than $1 \%$. Instead, patients are more likely to die of the complications of obstructive sleep apnoea, left ventricular dysfunction and complications of metabolic disorders, such as obesity and type 2 diabetes.

Data concerning treatment of patients with ES and DS are scarce. In a study looking at just seven people, it was found that six-minute walk distance (6MWD) and peripheral oxygen saturations increased with long-term bosentan treatment [5]. A multicentre study of ES, in which $31.9 \%$ of patients had DS, reported that the main predictors of death were age, oxygen saturations and the 
presence of pericardial effusions [6]. Based on data from 89 patients, 6MWD was a poor indicator of survival in WHO functional class I and II as performance was strongly influenced by factors such as mood and motivation on the day [7]. The study found little improvement in 6MWD with therapy, instead platelet count emerged as a better predictor of outcome.

\section{Case presentation}

Mr X is a 35-year-old patient with DS. He was diagnosed with an atrioventricular septal defect at nine months of age and is cared for by his elderly mother. He was in WHO functional class III, did not suffer from any presyncopal episodes and only experienced occasional haemoptysis. While his clinical parameters showed significant disease, he was clinically stable. He managed hobbies such as bowling, developed life skills through engagement in a local course and lived in supported community housing with friends. He was on no medication.

On examination, $\mathrm{Mr} \mathrm{X}$ was overweight with a BMI of 36 . He was cyanosed and had finger clubbing. He had a loud pulmonary heart sound and apical pan-systolic murmur on auscultation. His peripheral oxygen saturations were low, desaturating from $78-58 \%$ on the sixminute walk test and he only achieved a distance of 145 metres. Previous 6MWD were undertaken annually and these showed distances of $320 \mathrm{~m}, 280 \mathrm{~m}, 190 \mathrm{~m}$ over 6 years, 4 years and 2 years previous to the current one. His exercise oxygen saturations had fallen from $72-58 \%$ during the time in question.

Electrocardiogaphy revealed sinus rhythm but with right bundle branch block, superior axis and short runs of ventricular bigeminy. His echocardiogram displayed a complete atrioventricular septal defect. There was right ventricular hypertrophy and moderate left atrioventricular valve regurgitation with moderately good function (Tricuspid annular plane systolic excursion (TAPSE) of $15 \mathrm{~mm}$ ), though left ventricular systolic function was preserved with an ejection fraction of 58\%.

Serial blood tests were difficult to obtain since he was not usually compliant. His latest sample, taken 1 year previous showed NT-proBNP of $780 \mathrm{pg} / \mathrm{mL}$, haemoglobin $254 \mathrm{~g} / \mathrm{L}$, platelet count of $85 \times 10^{\wedge} 9 / \mathrm{L}$ and his creatinine was $105 \mathrm{micromol} / \mathrm{L}$.

Risk stratification scoring has not been validated for this group of patients, but for information the risk to our patient was intermediate. He had no right heart failure, syncope or right atrial dilation, but he did have progression of symptoms, WHO functional class III, 6 minute walk distance of $145 \mathrm{~m}$, and a raised BNP.

PAH therapies were offered but, given the stability of his condition, a formal 'best interests' meeting was held. At that meeting, Mr X's mother questioned whether her son actually required therapy, fearing that side-effects may outweigh any therapeutic benefits.

In the end, $\mathrm{Mr} \mathrm{X}$ and his family refused treatment. This was 11 years ago and he is now 46 years old and continues to enjoy hobbies with friends. From a cardiopulmonary perspective, he remains stable and has not experienced any further syncopal episodes, although he is exhibiting early signs of dementia.

\section{Discussion and conclusions}

The management of this patient posed some unique challenges. The indications and timing of initiation of PAH therapy in ES patients with DS remain unclear. While there is clear evidence that PAH therapies improve the exercise capacity and outcome of patients with idiopathic PAH and ES, reliably assessing the effects of $\mathrm{PAH}$ in DS patients is difficult and evidence is scarce, only consisting of case series demonstrating benefit [8]. There are also questions regarding the best first-line agent to use for the treatment of ES, although the strongest evidence is for bosentan [9] and also for tadalafil [10]. Recent studies have included patients with DS [11] but the overall numbers of patients with DS recruited in studies is small. Commissioning policy in the UK recommends first-line use of phosphodiesterase- 5 inhibitors for all types of $\mathrm{PAH}$, including patients with DS. While inappropriate erection is a potential side-effect and can be extremely embarrassing and uncomfortable for male patients, including those with DS, it is rarely encountered with long-term treatment.

This case also raises an important ethical dilemma: should physicians respect the mother's wishes, as the primary care giver, to refuse treatment, or does acting in the patient's best interests require that we insist on active treatment [12] ? Even if guidelines based on high quality research existed to resolve these issues, the patient's outcome may not have differed, as he and his family chose to refuse treatment. The current evidence for intervention in people with DS is lacking. The evidence for efficacy is generally based on an extension of that for other people with PAH. Anecdotal evidence from our clinics is that Pulmonary vasodilator therapy can be extremely effective in this group of patients and it seems most appropriate to let the family or carers take part in the discussion to decide whether it is best to add therapy or not depending on the effects on quality of life. Perhaps too often we assume intervention is the best approach to management and that patients' views will mirror our own. However, this case effectively highlights that patients and their families or carers can be entirely satisfied with conservative management, as long as they are fully informed of the available options and potential benefits/drawbacks. 


\section{Abbreviations}

PAH: Pulmonary arterial hypertension.: CHD: Congenital heart disease ES: Eisenmenger syndrome.; DS: Down syndrome.; TAPSE: Tricuspid annular plane systolic excursion.; 6MWD: Six-minute walk distance.

\section{Acknowledgements}

None.

\section{About this supplement}

This article has been published as part of Journal of Congenital Cardiology Volume 4 Supplement 1 2020: Unmet needs in Pulmonary Hypertension associated with Adult Congenital Heart Disease (ACHD-PH). The full contents of the supplement are available at https://jcongenitalcardiology. biomedcentral.com/articles/supplements/volume-4-supplement-1.

\section{Authors' contributions}

ZR and RT contributed to the design and writing of the article. All authors have read and approved the final manuscript.

\section{Authors' information}

Not applicable

\section{Funding}

Medical writing support was provided by nspm Itd, Meggen, Switzerland. The manuscript was funded by a Medical and Educational Goods and Services (MEGS) grant and Actelion Pharmaceuticals UK Limited (who had no influence on manuscript writing).

Professor Tulloh is supported by the NIHR Biomedical Centre at the University Hospitals Bristol NHS Foundation Trust and the University of Bristol.

\section{Availability of data and materials}

Not applicable.

\section{Ethics approval and consent to participate}

Not applicable.

\section{Consent for publication}

Consent was not possible for this case, due to lack of capacity, but the information is anonymised to protect the individual. Verbal agreement was provided by carers.

\section{Competing interests}

Professor Robert Tulloh has received unrestricted educational, travel or research grants from Bayer, Pfizer, Actelion and GSK. Zoya Rashid has received a travel grant from Actelion pharmaceuticals.

Received: 12 November 2020 Accepted: 12 November 2020

Published: 16 December 2020

\section{References}

1. Galie N, Humbert M, Vachiery JL, Gibbs S, Lang I, Torbicki A, et al. 2015 ESC/ ERS Guidelines for the diagnosis and treatment of pulmonary hypertension: The Joint Task Force for the Diagnosis and Treatment of Pulmonary Hypertension of the European Society of Cardiology (ESC) and the European Respiratory Society (ERS): Endorsed by: Association for European Paediatric and Congenital Cardiology (AEPC), International Society for Heart and Lung Transplantation (ISHLT). Eur Respir J. 2015.

2. Bradford R, Tulloh R. Diagnosis and Management of Pulmonary hypertension in adult congenital heart disease. Br J Cardiac Nurs. 2008;3: 138-45.

3. King P, Tulloh R. Management of pulmonary hypertension and Down syndrome. International journal of clinical practice Supplement. 2011;174:8-13.

4. Korten MA, Helm PC, Abdul-Khaliq H, Baumgartner H, Kececioglu D, Schlensak $C$, et al. Eisenmenger syndrome and long-term survival in patients with Down syndrome and congenital heart disease. Heart. 2016 102(19):1552-7.

5. Crepaz R, Romeo C, Montanaro D, De Santis S. Long-term results of treatment with bosentan in adult Eisenmenger's syndrome patients with Down's syndrome related to congenital heart disease. BMC Cardiovasc Disord. 2013;13:74
6. Kempny A, Hjortshoj CS, Gu H, Li W, Opotowsky AR, Landzberg MJ, et al Predictors of Death in Contemporary Adult Patients With Eisenmenger Syndrome: A Multicenter Study. Circulation. 2017;135(15):1432-40.

7. Shortland J, Herbert S, Pascall E, Leonard K, Howard L, Tulloh R. Is the 6 minute walk test or platelet count helpful in determining prognosis of patients with Eisenmenger Syndrome and Down syndrome? Cardiol Young. 2015;25(supplement 1):181-90.

8. Duffels MG, Vis JC, van Loon RL, Berger RM, Hoendermis ES, van Dijk AP, et al. Down patients with Eisenmenger syndrome: is bosentan treatment an option? Int J Cardiol. 2009;134(3):378-83.

9. Gatzoulis MA, Rogers P, Li W, Harries C, Cramer D, Ward S, et al. Safety and tolerability of bosentan in adults with Eisenmenger physiology. Int J Cardiol. 2005;98(1):147-51.

10. Mukhopadhyay S, Nathani S, Yusuf J, Shrimal D, Tyagi S. Clinical efficacy of phosphodiesterase-5 inhibitor tadalafil in Eisenmenger syndrome-a randomized, placebo-controlled, double-blind crossover study. Congenit Heart Dis. 2011;6(5):424-31.

11. Gatzoulis MA, Landzberg M, Beghetti M, Berger RM, Efficace M, Gesang S, et al. Evaluation of Macitentan in Patients With Eisenmenger Syndrome. Circulation. 2019:139(1):51-63.

12. Dimond B. The Mental Capacity Act 2005 and decision-making: best interests. Br J Nurs. 2007:16(19):1208-10.

\section{Publisher's Note}

Springer Nature remains neutral with regard to jurisdictional claims in published maps and institutional affiliations.
Ready to submit your research? Choose BMC and benefit from:

- fast, convenient online submission

- thorough peer review by experienced researchers in your field

- rapid publication on acceptance

- support for research data, including large and complex data types

- gold Open Access which fosters wider collaboration and increased citations

- maximum visibility for your research: over $100 \mathrm{M}$ website views per year

At $\mathrm{BMC}$, research is always in progress.

Learn more biomedcentral.com/submission 